\title{
Effect of Stress Level on the High Temperature Deformation and Fracture Mechanisms of Ti-45Al-2Nb-2Mn-0.8 vol. pct TiB 2 : An In Situ Experimental Study
}

\author{
ROCÍO MUÑOZ-MORENO, M. TERESA PÉREZ-PRADO, JAVIER LLORCA, \\ ELISA MARÍA RUIZ-NAVAS, and CARL J. BOEHLERT
}

\begin{abstract}
The effect of the applied stress on the deformation and crack nucleation and propagation mechanisms of a $\gamma$-TiAl intermetallic alloy (Ti-45Al-2Nb-2Mn (at. pct)-0.8 vol. pct $\mathrm{TiB}_{2}$ ) was examined by means of in situ tensile (constant strain rate) and tensile-creep (constant load) experiments performed at $973 \mathrm{~K}\left(700{ }^{\circ} \mathrm{C}\right)$ using a scanning electron microscope. Colony boundary cracking developed during the secondary stage in creep tests at 300 and $400 \mathrm{MPa}$ and during the tertiary stage of the creep tests performed at higher stresses. Colony boundary cracking was also observed in the constant strain rate tensile test. Interlamellar ledges were only found during the tensile-creep tests at high stresses $(\sigma>400 \mathrm{MPa})$ and during the constant strain rate tensile test. Quantitative measurements of the nature of the crack propagation path along secondary cracks and along the primary crack indicated that colony boundaries were preferential sites for crack propagation under all the conditions investigated. The frequency of interlamellar cracking increased with stress, but this fracture mechanism was always of secondary importance. Translamellar cracking was only observed along the primary crack.
\end{abstract}

DOI: $10.1007 / \mathrm{s} 11661-012-1515-8$

(c) The Minerals, Metals \& Materials Society and ASM International 2012

\section{INTRODUCTION}

GAMMA titanium aluminides are important intermetallic alloys targeted for high-temperature structural applications because they can provide increased thrust-to -weight ratios and improved efficiency.$^{[1,2]}$ For instance, the blades in the low-pressure section of gas turbines have to operate in aggressive environments at temperatures up to $973 \mathrm{~K}\left(700^{\circ} \mathrm{C}\right)$, where gamma titanium aluminides present reasonably good creep and oxidation resistance. ${ }^{[3]}$ Thus, such alloys have the potential to replace the heavier Ni-base superalloys currently used. However, their hightemperature deformation behavior must be better understood to optimize their microstructure. ${ }^{[4-10]}$

Gamma titanium aluminides contain two phases $\left(\gamma\right.$-TiAl, tetragonal $\mathrm{L}_{0}$ structure and $\alpha_{2}-\mathrm{Ti}_{3} \mathrm{Al}$, hexagonal $\mathrm{DO}_{19}$ structure) and may exhibit various microstructures consisting of different volume fractions of

ROCÍO MUÑOZ-MORENO, Research Assistant and Ph.D. Candidate, is with the IMDEA Materials Institute, Madrid, Spain, and also with the Department of Materials Science and Engineering, Carlos III University, Madrid, Spain. Contact e-mail: rocio.munoz@imdea.org M. TERESA PÉREZ-PRADO, Senior Scientist, is with the IMDEA Materials Institute. JAVIER LLORCA, Director and Professor of Materials Science, is with the IMDEA Materials Institute, and also with the Polytechnic University of Madrid, Madrid, Spain. ELISA MARÍA RUIZ-NAVAS, Professor, is with the Department of Materials Science and Engineering, Carlos III University. CARL J. BOEHLERT, Associate Professor and Visiting Scientist, is with the IMDEA Materials Institute, and Polytechnic University of Madrid, and also with the Department of Chemical Engineering and Materials Science, Michigan State University, East Lansing, MI.

Manuscript submitted July 11, 2012.

Article published online November 10, 2012 equiaxed $\gamma$ grains and of $\left(\alpha_{2}+\gamma\right)$ lamellar colonies. ${ }^{[3,11]}$ They are termed duplex (comprising a mixture of equiaxed grains and lamellar colonies), nearly lamellar (containing only a small fraction of equiaxed grains) and fully lamellar (no equiaxed grains). Lamellar colonies have $\alpha_{2} / \gamma$ and $\gamma / \gamma$ lamellae oriented according the Blackburn relationship $(0001)_{\alpha_{2}}\{111\}_{\gamma},\left.11 \overline{2} 0_{\alpha_{2}} 1 \overline{1} 0\right|_{\gamma} .{ }^{[12]}$ The mechanical properties depend on the microstructure and composition. In general, fully lamellar microstructures exhibit enhanced creep resistance and acceptable fracture toughness, while the duplex microstructures exhibit higher elongation-to-failure. ${ }^{[13,14]}$

At room temperature, $\gamma$-TiAl alloys are characterized by a high plastic anisotropy. Deformation is accomplished through ordinary slip and mechanical twinning in the $\gamma$-phase. ${ }^{[15,16]}$ Thermal activation promotes dislocation cross-slip and climb at high temperature, enhancing plastic deformation and reducing the plastic anisotropy. Microstructural instabilities have also been reported to occur at high temperatures. ${ }^{[3,15,17]}$ At temperatures above $923 \mathrm{~K}\left(650{ }^{\circ} \mathrm{C}\right)\left(T>0.4 T_{\mathrm{m}}\right), \gamma$-TiAl alloys are susceptible to creep. These materials usually exhibit a limited secondary-creep region, characterized by the absence of a steady state, in which the creep rate reaches a minimum and then increases with strain leading to the tertiary stage. ${ }^{[15,18]}$ The minimum creep rate $\left(\dot{\varepsilon}_{\text {Min }}\right)$ depends on, apart from the temperature and stress, the alloy chemistry and microstructure.$^{[15,19]}$ In polysynthetically twinned (PST) TiAl, the minimum creep rate varies as a function of the relative orientation between the lamellae and the applied stress. The lowest minimum creep rates are found when the lamellae are oriented either parallel or perpendicular to the stress 
axis, while the highest minimum creep rates occurred when the lamellae are oriented $45 \mathrm{deg}$ with respect to the stress axis. ${ }^{[20,21]}$ In polycrystals, the application of the Dorn approach has rendered wide variations of the stress exponents, $n$, and the activation energies for creep, $Q_{\text {c }}$, suggesting that several mechanisms operate simultaneously during creep of $\alpha_{2}+\gamma$ TiAl alloys. ${ }^{[15,22-24]}$ Diffusion-based mechanisms are dominant at low stresses, while dislocation creep becomes more important at higher stresses. However, the contribution from other mechanisms such as grain boundary sliding is not clear. ${ }^{[8-10,25]}$ Further study is therefore needed to clarify the mechanisms responsible for high-temperature deformation of these intermetallic alloys.

Lamellar microstructures are known to have greater fracture toughness than duplex ones. This is due to crack deflection at lamellar interfaces and to the development of crack-bridging ligaments and microcracking in the lamellae. ${ }^{[3]}$ With increasing temperature, the fracture toughnesses of both lamellar and duplex structures increase, but this effect is most pronounced in the latter. ${ }^{[15]}$ Crack propagation mechanisms depend on the temperature. At room temperature in lamellar microstructures, cracks can propagate both across lamellae (translamellar) and at lamellae interfaces (interlamellar), depending on the orientation of the lamellas with respect to the loading axis. ${ }^{[19,21,26]}$ In duplex microstructures, transgranular cracks predominate. ${ }^{[3]}$ At high temperatures, colony boundaries and, in particular, triple points, are favorable sites for crack nucleation in lamellar microstructures. ${ }^{[10,22]}$ Colony sliding promotes the nucleation of wedge cracks which propagate along colony boundaries. Nevertheless, further study is needed to understand better the crack nucleation and propagation mechanisms.

Using conventional testing methods, the deformation and failure mechanisms may be inferred from the observation of the microstructural changes caused by mechanical testing, as well as from the shape of the stress-strain curves. These ex-situ experiments have limitations as it is not possible to know the order of activation of the different deformation modes or the stress or strain at which they occur during the experiment. These disadvantages can be overcome by utilizing in situ testing methods which allow for the observation of the evolution of the surface microstructure in real time and therefore facilitate the study of the kinetics of the deformation and failure mechanisms. ${ }^{[10,27-30]}$

The primary aim of this study was to investigate the deformation and failure mechanisms operative during elevated-temperature tensile-creep deformation of a Ti-45Al-2Nb-2Mn (at. pct)-0.8 vol. pct $\mathrm{TiB}_{2}$ intermetallic at different stresses. A thorough understanding of these mechanisms would allow for better development of methods for microstructural optimization, which lead to a delay in crack initiation and propagation, thereby enhancing the intermetallic's life. With that purpose, in situ tensile and tensile-creep experiments were performed on a scanning electron microscope (SEM) at $973 \mathrm{~K}\left(700^{\circ} \mathrm{C}\right)$, and the evolution of the microstructure with time was characterized. In a previous study, a transition in the dominating crack propagation path, from interlamellar to intercolonial, was observed below a threshold applied stress. ${ }^{[10]}$ This investigation was intended to build on this knowledge to understand the importance of intercolonial, interlamellar and translamellar cracking as a function of the stress level.

\section{EXPERIMENTAL}

The nominal composition of the intermetallic was Ti-45Al-2Nb-2Mn (at. pct)- 0.8 vol. pet $\mathrm{TiB}_{2}$, while the bulk alloy composition (as measured by fluorescence) was (in at. pet): 50.6 pet Ti; 44.1 pet Al; 2.0 pet Nb; 2.2 pet $\mathrm{Mn} ; 0.04$ pet $\mathrm{Si} ; 0.02$ pet $\mathrm{C} ; 0.86$ pet $\mathrm{O} ; 0.05$ pet $\mathrm{Fe}$; 0.04 pet $\mathrm{H} ; 0.01$ pet $\mathrm{N} ; 0.86$ pet $\mathrm{B}$. The alloy was provided by GfE (Gesellschaft für Elektrometallurgie $\mathrm{mbH}$ ) and was processed by centrifugal casting at ACCESS e. V. TechCenter (Aachen, Germany). The dimensions of the castings were $44 \mathrm{~mm}$ by $20 \mathrm{~mm}$ by $2.5 \mathrm{~mm}$ (Figure 1). The cast specimens were hot isostatically pressed at $1458 \mathrm{~K}\left(1185^{\circ} \mathrm{C}\right)$ and $1700 \mathrm{bar}$

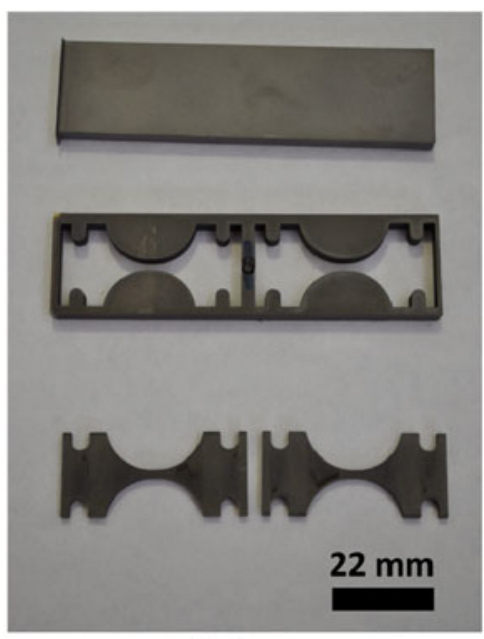

(a)

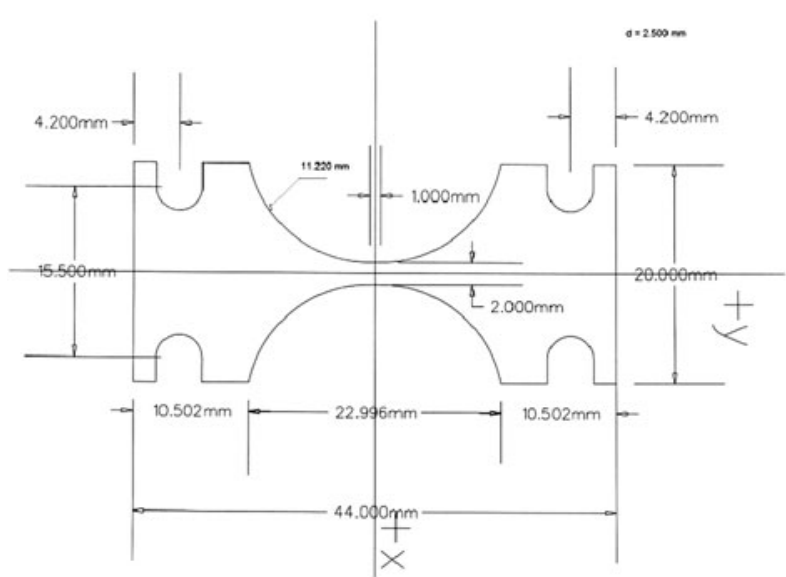

(b)

Fig. 1-The mechanical test specimens were machined from centrifugal cast rectangular bars as illustrated in $(a)$. A schematic of the specimen geometry is provided in $(b)$. 
for four hours to remove any remnant porosity in the castings.

Microstructure analysis was performed using optical microscopy (OM), SEM and transmission electron microscopy (TEM). OM analysis was performed using an Olympus (U.K.) BX-51 optical microscope. SEM analysis was carried out using a Zeiss (Jena, Germany) EVO MA15 equipped with an Energy Dispersive Spectroscopy (EDS) system (Oxford INCAx-act). Samples for microstructural examination were cut with a diamond disk and mounted in an epoxy resin. They were then polished using silicon carbide paper and diamond paste with the final polish of $0.06 \mu \mathrm{m}$ using colloidal silica. TEM analysis was performed using FEI Instruments (Oregon, USA) model Tecnai T20 TEM at $200 \mathrm{kV}$. The TEM foils were prepared by polishing the samples to a thickness of approximately $200 \mu \mathrm{m}$, then punching $3 \mathrm{~mm}$-diameter disks, and finally thinning them using a Struers (Ballerup, Denmark) twinjet Tenupol-5 electropolisher until perforation. The electropolishing solution, which consisted of 5 pct perchloric acid, 35 pet butanol, and 60 pet methanol, was held at a constant temperature of $243 \mathrm{~K}$ with a voltage of $40 \mathrm{~V}$. The volume percent of the phases was measured using Image $\mathbf{J}$ (Bethesda, MD) software on several backscattered electron SEM images. The average colony size, obtained from more than 90 colonies, was determined using the ASTM grain size standard. ${ }^{[31]}$ The average lamellar width of both phases, $\lambda$, was measured using several bright field TEM images, in the "edge-on" condition, and dark field imaging. The $\alpha_{2}$ lamellar thickness was examined by isolating the (0001) $\alpha_{2}$ diffraction spot of the $\alpha_{2}$ selected area diffraction pattern (SADP), which overlaps the $\langle 110\rangle$ SADP of the $\gamma$ phase according to the $(0001)_{\alpha_{2}}||\{111\}_{, 2}\langle 11 \overline{2} 0\rangle_{\alpha_{2}} \|\left\langle\left. 1 \overline{1} 0\right|_{\gamma}\right.$, Blackburn orientation relationship. ${ }^{[12]}$ By comparing the $\alpha_{2}$ lamellar width with $\lambda$, the $\gamma$ lamellae width was obtained.

In situ tensile and tensile-creep experiments were conducted at $973 \pm 30 \mathrm{~K}$. Two samples were tensile tested at an approximate strain rate of $10^{-3} \mathrm{~s}^{-1}$. Ten tensile-creep experiments were conducted at stresses between 300 and $450 \mathrm{MPa}$. The samples were electrodischarge machined from the cast specimens with the geometry illustrated in Figure 1. The specimens were polished through a final finish of $0.06 \mu \mathrm{m}$ using colloidal silica. The in situ tests were performed using a screwdriven tensile stage placed inside the SEM. Temperature was controlled using a constant-voltage power supply to a 6-mm-diameter tungsten-based heater located just below the gage section of the sample. An open-bath, closed-loop chiller was used to circulate distilled water at $288 \mathrm{~K}\left(15^{\circ} \mathrm{C}\right)$ through copper tubes to prevent the tensile stage from overheating. A fine-gage K-type thermocouple was placed against the gage section of each sample. After the sample's gage-section temperature reached the desired creep temperature, the sample was held by at least 30 minutes before applying load to stabilize the temperature. The load was measured using a 4,448 N load cell and was applied at $5 \mathrm{~N} / \mathrm{s}$ until reaching the desired creep stress for the tensile-creep experiments. The pressure in the SEM chamber never exceeded $4 \times 10^{-6} \mathrm{~T}$, and therefore oxidation did not detrimentally affect the SEM imaging. Further details of this apparatus and testing technique can be found elsewhere. ${ }^{[10,27-30]}$

Backscattered electron (BSE) SEM images were taken before and after the experiments, and secondary electron (SE) SEM images were taken at periodic displacements throughout tests without interrupting the experiment. The strain values were estimated from the displacement measurements taking into account the heated gage length of the samples.

\section{RESULTS}

\section{A. Microstructure}

The centrifugal cast intermetallic exhibited a polycrystalline lamellar microstructure with a minority fraction (0.18) of equiaxed $\alpha_{2}$ and $\gamma$ grains located at colony boundaries (Figure 2). Therefore the microstructure was considered to be nearly lamellar (NL). The B-rich phase was located both inside the colonies and at the colony boundaries and typically exhibited a lacey shape, as has been observed previously. ${ }^{[32]}$ The average volume fractions of the $\gamma$ and $\alpha_{2}$ phases were 0.69 and 0.31 , respectively. The lamellar colony diameter ranged from 26 to $164 \mu \mathrm{m}$, with an average diameter, determined from 92 different colonies, of $126 \mu \mathrm{m}$ and a standard deviation of $52 \mu \mathrm{m}$. Figure 3 illustrates the fine nature of the lamellae. The average lamellar thicknesses of the $\alpha_{2}$ and $\gamma$ phases were 329 and $480 \mathrm{~nm}$, respectively, and $\lambda$ was $422 \mathrm{~nm}$.

\section{B. Tensile Deformation}

Figure 4 depicts the tensile stress-strain curve and the corresponding SEM micrographs obtained at various stress levels during the constant strain rate test (Figures 4(b)-(e)). The maximum stress borne by the material, $\sigma_{\max }$, was $460 \mathrm{MPa}$. The micrographs show that interlamellar ledges

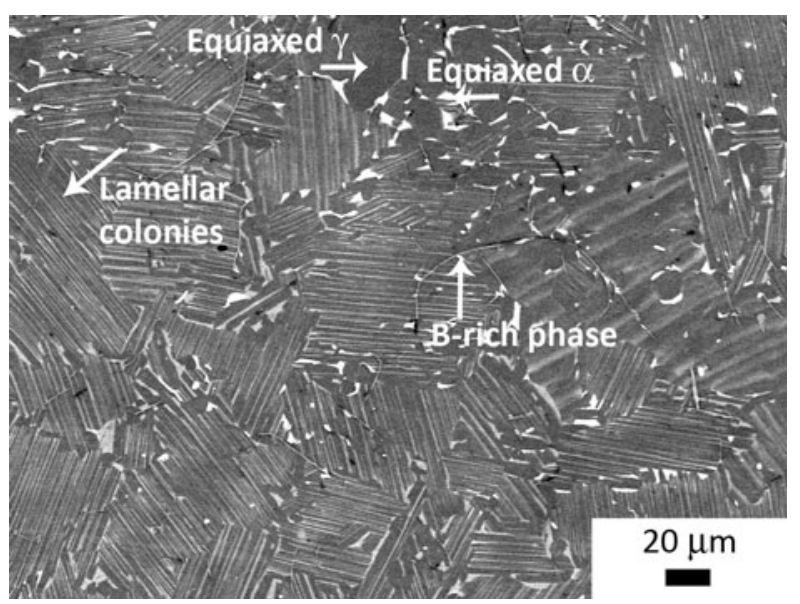

Fig. 2-BSE SEM photomicrograph of the NL microstructure, where the bright zones stand for the $\alpha_{2}$ phase, the dark zones are the $\gamma$ phase, and the lacey-shaped phase is the B-rich phase. 


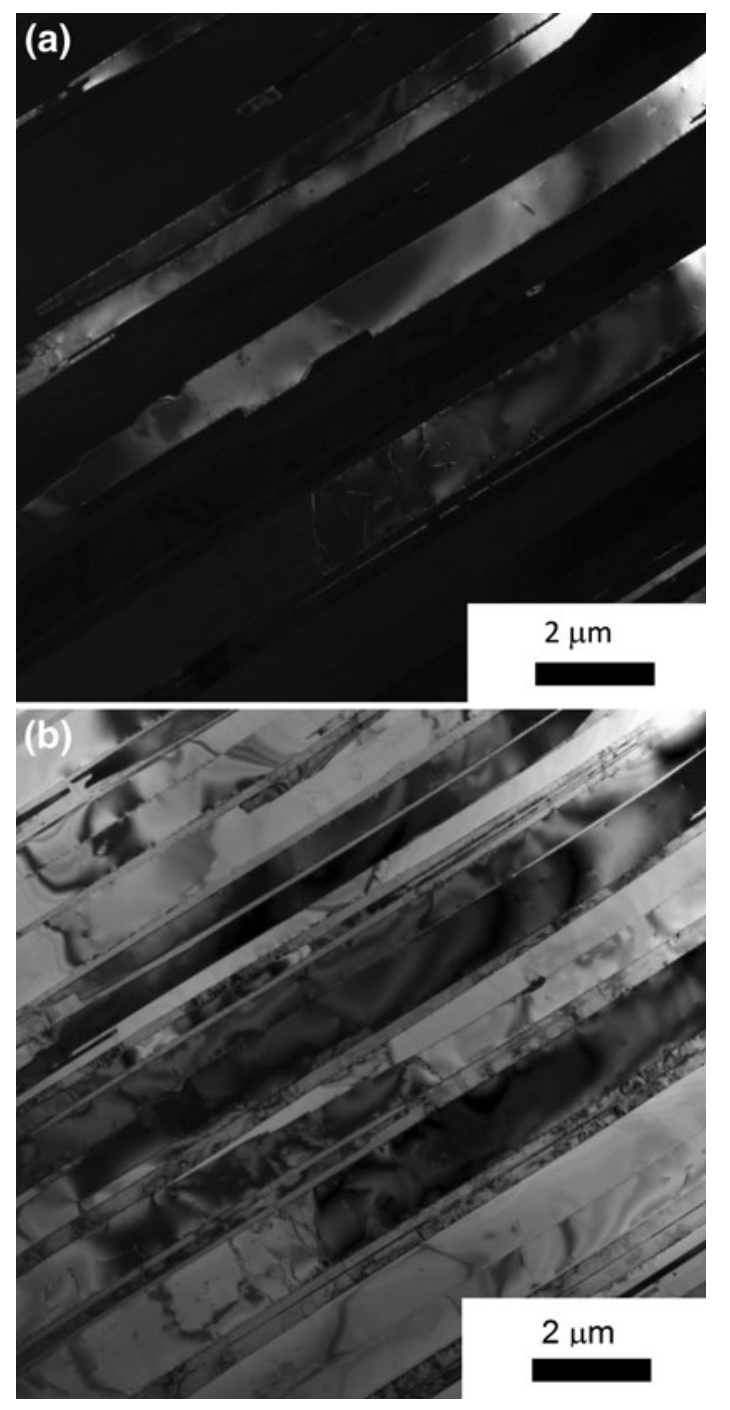

Fig. 3-(a) Dark-field (where the $\alpha_{2}$ phase lamellas are brighter) and (b) bright-field TEM images taken from an identical lamellar region inside a colony.

(highlighted in Figure 4 using white arrows) became more pronounced with deformation. Interlamellar ledges were first observed at a stress of $374 \mathrm{MPa}$ and a strain value of $\varepsilon \sim 0.8$ pct (Figure 4(b)). Lacey borides were observed to crack at intermediate strains close to the yield stress (see black arrows in Figure 4(c)). Finally, ledges at colony boundaries were detected at higher strains (dashed arrows in Figures 4(d), (e)).

\section{Creep Deformation}

The microstructural evolution during the creep tests at $300 \mathrm{MPa}\left(0.65 \sigma_{\max }\right)$ and $400 \mathrm{MPa}\left(0.86 \sigma_{\max }\right)$ was similar. Figure 5 shows several SEM micrographs taken at various strain levels of the tensile-creep test performed at $300 \mathrm{MPa}$. During the secondary-creep regime, surface relief at the colony boundaries was increasingly evident, suggesting the presence of colony boundary sliding. Crack nucleation and propagation at the colony boundaries was observed during the secondary regime
(Figure 6(a)) (at strains of above $0.4 \mathrm{pct}$ ) and continued into the tertiary-creep regime (Figure 6(b)). The B-rich phase particles were susceptible to brittle fracture at even lower strains (Figure 6). The primary crack path followed colony boundaries, as shown in Figures 5(c)-(e). For a specimen tested at $400 \mathrm{MPa}$, crack nucleation at the colony boundary was first detected at a strain of 0.6 pct, and B-rich phase particles were observed to crack (Figure 7) after 0.2 pet strain. No interlamellar ledge formation was observed for the samples.

The deformation and fracture mechanisms at $425 \mathrm{MPa}\left(0.92 \sigma_{\max }\right)$ and $450 \mathrm{MPa}\left(0.98 \sigma_{\max }\right)$ were different from those observed at lower stresses. Representative SEM images corresponding to the test performed at $425 \mathrm{MPa}$ are shown in Figure 8. The most remarkable observation is that interlamellar ledges become apparent from the beginning of the secondary stage (Figure 8(a)). In particular, interlamellar ledges were first detected at strains of 0.3 and 0.1 pct at 425 and $450 \mathrm{MPa}$, respectively. They are shown in Figure 9 in the tensile-creep test at $450 \mathrm{MPa}$. This is similar to what was observed during the tensile test. For these higher stress tensile-creep tests, colony boundary cracking was limited to the tertiary stage (Figure 8(b)). B-rich phase cracking was also observed at these conditions.

The secondary cracks and the primary crack of the tested samples were analyzed to understand the crack propagation. The tensile-tested samples and tensilecreep samples at 300 and $450 \mathrm{MPa}$ were analyzed. The classification of the different secondary cracks (Figure 10(a)), along a 600- $\mu$ m-long section in the center of the sample, illustrated that the main fracture mechanism was intercolony cracking for all the tests conditions. This mechanism was more prevalent at the lowest strain rates. Some interlamellar cracks were also detected but this mechanism was of less importance. Translamellar secondary cracks were rarely observed. The nature of crack propagation along the primary crack path was characterized across approximately 40 colonies, and the results are plotted in Figure 10(b). They show that colony boundary fracture and translamellar cracking were the main fracture mechanisms along the main crack. The former was dominant in the creep test at $300 \mathrm{MPa}$ while the latter prevailed in the tensile test.

\section{DISCUSSION}

Understanding the high-temperature deformation and crack propagation mechanisms of fully lamellar and nearly lamellar $\gamma$-TiAl alloys is challenging for several reasons. First, attempts to rationalize the creep data in terms of conventional methods, such as the Dorn approach, are quite controversial ${ }^{[15,22]}$ as only a short, secondary-creep stage exists. Nevertheless, several studies have utilized this methodology ${ }^{[33-41]}$ in an effort to determine the dominant deformation mechanisms. The large range of stress exponents and activation energies obtained points toward the simultaneous contribution of several deformation mechanisms, but the nature and incidence of each of them is unknown. Second, the wide array of microstructures and compositions available 


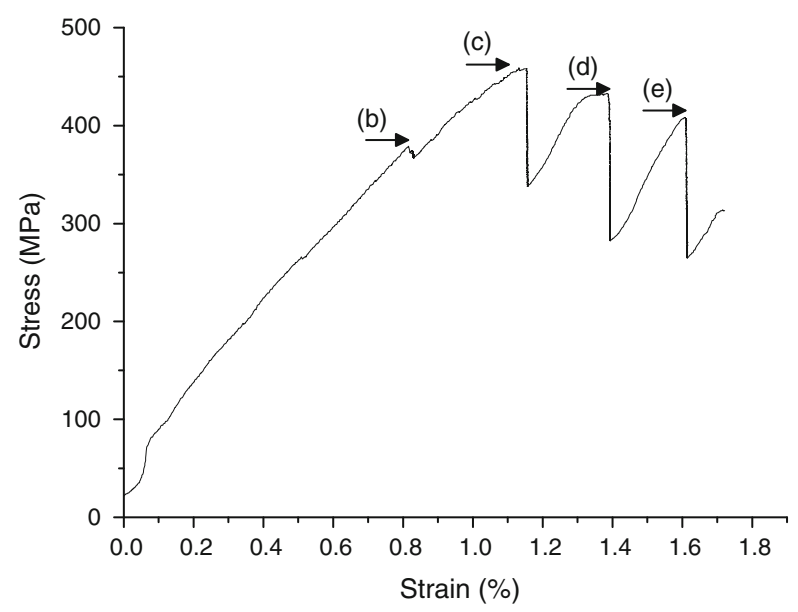

(a)

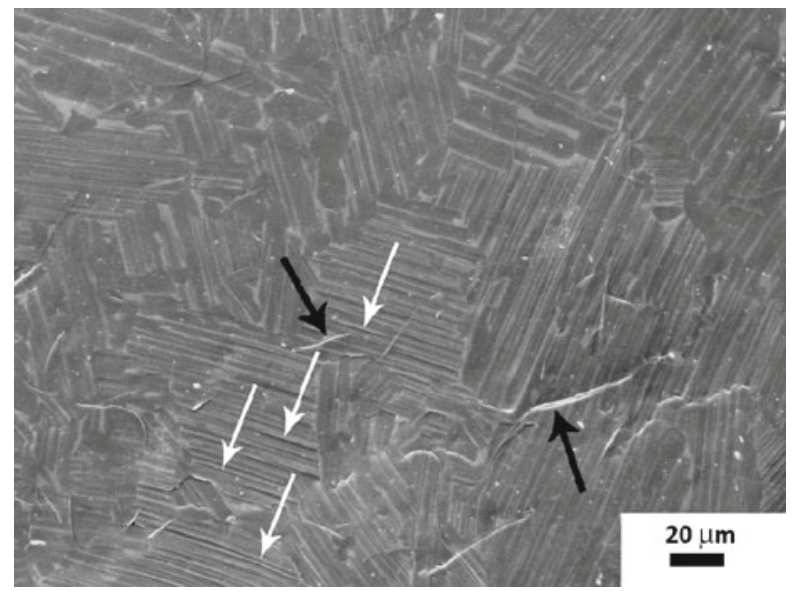

(c)

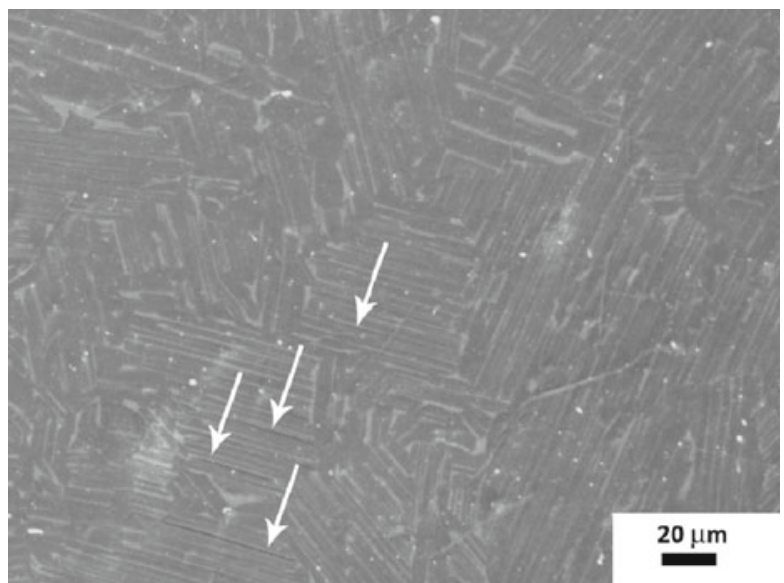

(b)

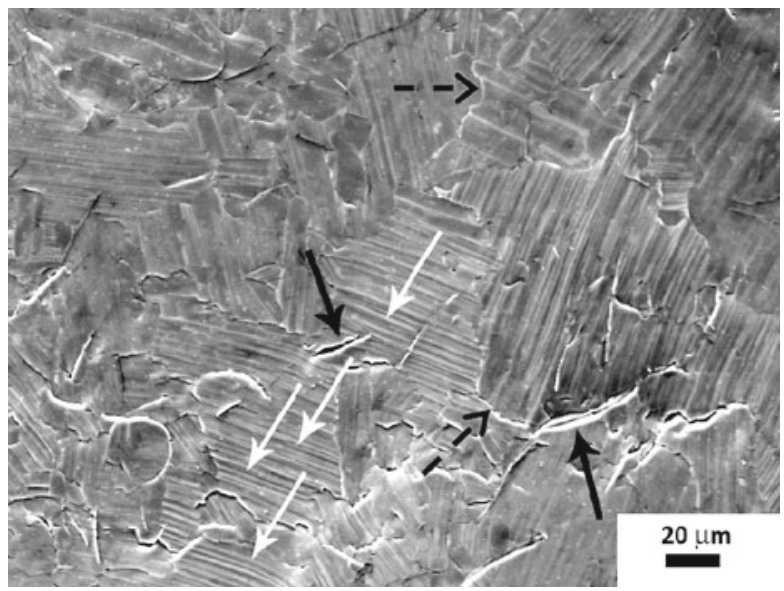

(d)

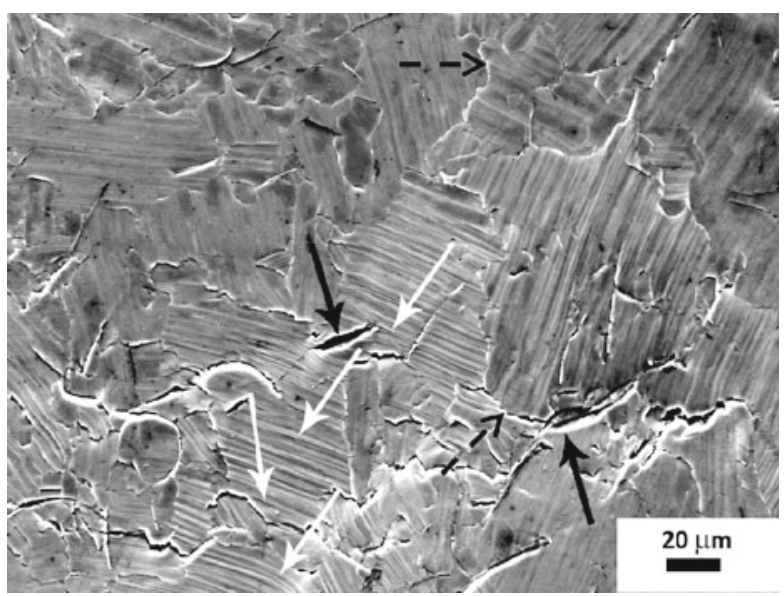

(e)

Fig. 4 - (a) Stress-strain curve corresponding to a tensile test at $973 \mathrm{~K}\left(700{ }^{\circ} \mathrm{C}\right)$ at a constant strain rate of $10^{-3} \mathrm{~s}^{-1}$ with indications where micrographs $(b-e)$ were taken. Sequence of SE SEM photomicrographs obtained with increasing time: (b) $\sigma=374 \mathrm{MPa}, \varepsilon \sim 0.8$ pct; (c) $\sigma=459 \mathrm{MPa}, \varepsilon \sim 1.2 \mathrm{pct}$; (d) $\sigma=433 \mathrm{MPa}, \varepsilon \sim 1.4 \mathrm{pct}$; (e) $\sigma=408 \mathrm{MPa}, \varepsilon \sim 1.6$ pct. White arrows point toward interlamellar relief, black arrows highlight reinforcement cracks, and dashed arrows show the initiation of intercolony cracks; The loading axis is vertical.

make it very difficult to devise general creep models for these alloys. The influence of microstructural parameters such as the colony size, the lamella size, the nature of the colony boundaries, or the presence of secondphase particles is still unclear.
Most creep studies are performed under temperatures and stresses similar to those prevalent under service conditions, i.e., at temperatures ranging from $923 \mathrm{~K}$ to $1123 \mathrm{~K}\left(650^{\circ} \mathrm{C}\right.$ to $\left.850{ }^{\circ} \mathrm{C}\right)$ and with the stresses ranging from 80 to $500 \mathrm{MPa}$. These conditions are within the 


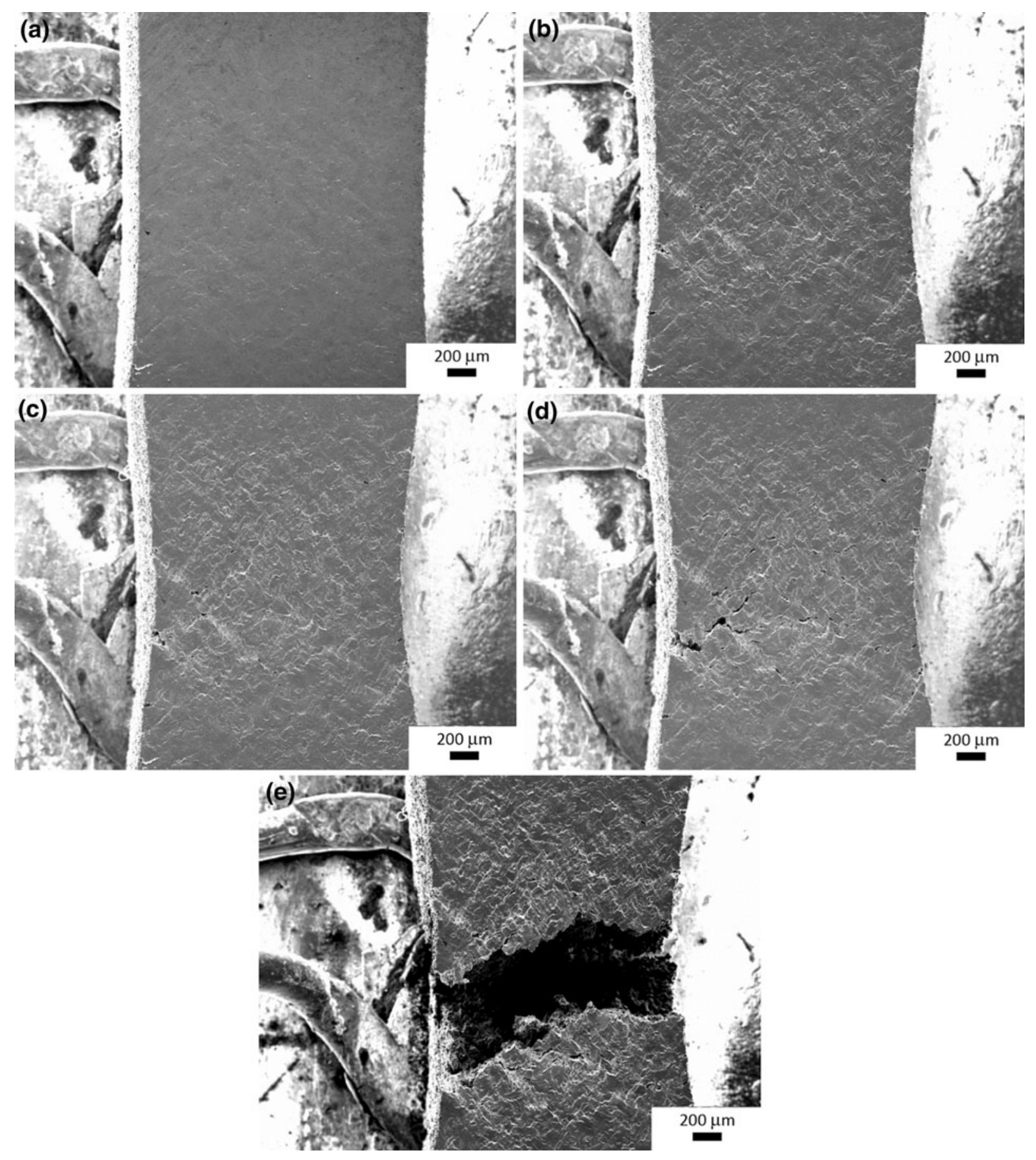

Fig. 5- Sequence of low-magnification SE SEM photomicrographs from a tensile-creep test performed at 300 MPa: (a) Secondary-creep stage, $46 \mathrm{~h}, \varepsilon \sim 0.4 \mathrm{pct} ;(b)$ tertiary-creep stage, $72 \mathrm{~h}, \varepsilon \sim 1.2 \mathrm{pct}$; $(c)$ tertiary-creep stage, $75 \mathrm{~h}, \varepsilon \sim 1.4 \mathrm{pct}$; $(d)$ tertiary-creep stage just before fracture, $76 \mathrm{~h}, \varepsilon \sim 1.5 \mathrm{pct}$; (e) after fracture, $76 \mathrm{~h}, \varepsilon \sim 1.6 \mathrm{pct}$. The loading axis is vertical.

range utilized in the current study. It is generally believed that dislocation slip and mechanical twinning are active during the secondary-creep stage of $\gamma$-TiAl alloys. ${ }^{[15]}$ In particular, dislocation climb would be the rate-controlling process at stresses below a certain threshold, depending on the colony size, ${ }^{[36]}$ and dislocation glide at higher stresses. Recent in situ study by the authors ${ }^{[10]}$ pointed toward the occurrence of colony boundary sliding (CBS) at low stresses (250 MPa). Interface sliding has also been inferred from ex-situ studies. ${ }^{[41-43]}$ In particular, CBS was reported to occur in a $45 \mathrm{XD}$ alloy, ${ }^{8]}$ with a colony size less than $100 \mu \mathrm{m}$, subjected to creep deformation in tension at $1023 \mathrm{~K}$ $\left(750{ }^{\circ} \mathrm{C}\right)$ up to stresses of $200 \mathrm{MPa}$. The results shown in this article confirm the importance of CBS during the secondary creep stage for Ti-45Al-2Mn-2Nb-0.8 vol. pct 

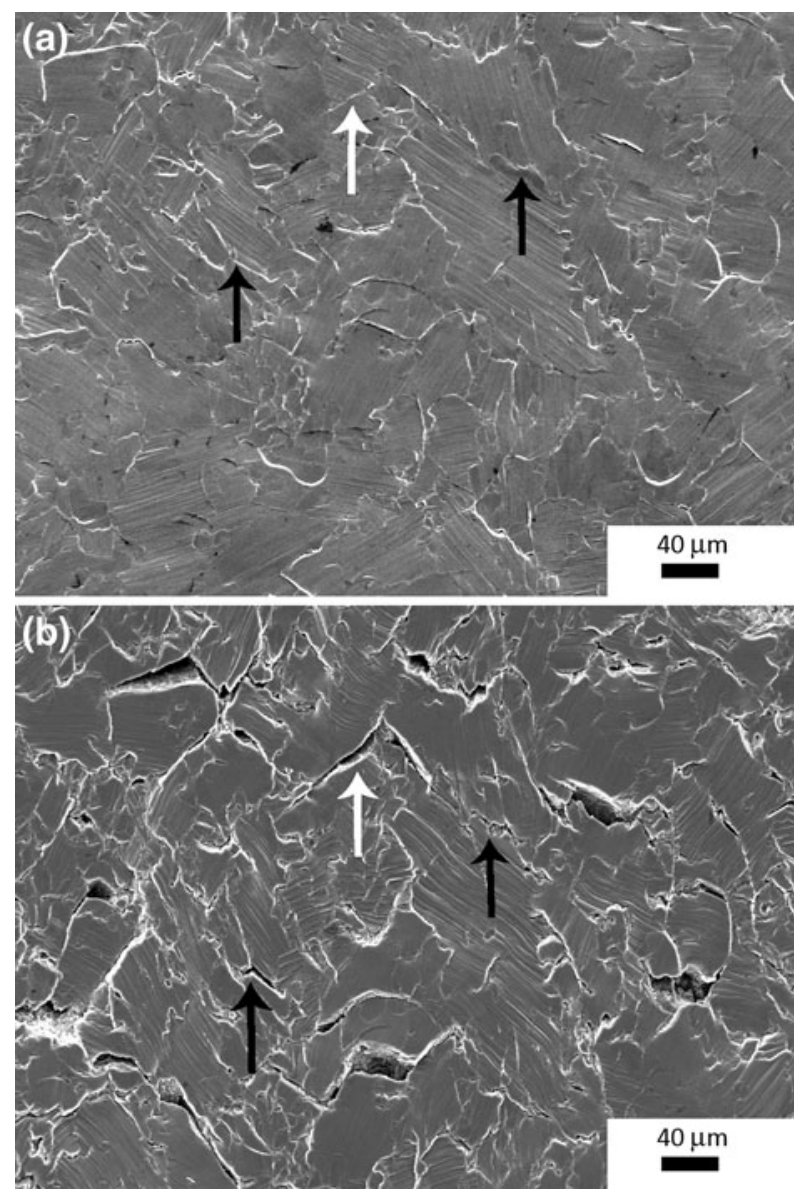

Fig. 6-SE SEM photomicrographs obtained during a creep experiment at $300 \mathrm{MPa}(a)$ Secondary stage, $50 \mathrm{~h}$ and $\varepsilon \sim 0.5 \mathrm{pct}(b)$ Tertiary stage, $76 \mathrm{~h}$ and $\varepsilon \sim 1.5$ pct (White arrow points B-rich phase cracking and black arrows point colony boundary cracks). The loading axis is vertical.

$\mathrm{TiB}_{2}$. Furthermore, this mechanism appears to be active at relatively high stresses, up to about $400 \mathrm{MPa}$, even when the colony size $(126 \mu \mathrm{m})$ is larger than the critical size proposed previously $(100 \mu \mathrm{m})$. This suggests that special care must be taken in reinforcing the colony boundary sliding resistance if the creep resistance of $\gamma$-TiAl alloys under service conditions is to be improved. At stresses greater than $400 \mathrm{MPa}$, interlamellar ledges were observed during the early stages of the secondarycreep regime. These were probably caused by the need to accommodate strain incompatibilities resulting from dislocation sliding between adjacent lamellae. CBS was limited to the tertiary stage. These observations are consistent with the prevalence of dislocation slip during the secondary stage at these very high creep stresses or, equivalently, during high constant strain rate tests at the quasi-static rates investigated.

Some authors have reported the occurrence of instabilities during creep of $\gamma$-TiAl alloys. For example, Wang et al. ${ }^{[43]}$ reported that, together with dislocation activity and some twinning, thinning and dissolution of $\alpha_{2}$ lamellae and coarsening of $\gamma$-lamellae took place during creep of a fully lamellar Ti-47Al $+2 \mathrm{Cr}+$ $2 \mathrm{Nb}$ and $\mathrm{Ti}-47 \mathrm{Al}+2 \mathrm{Cr}+1 \mathrm{Nb}+1 \mathrm{Ta}$ at high stresses
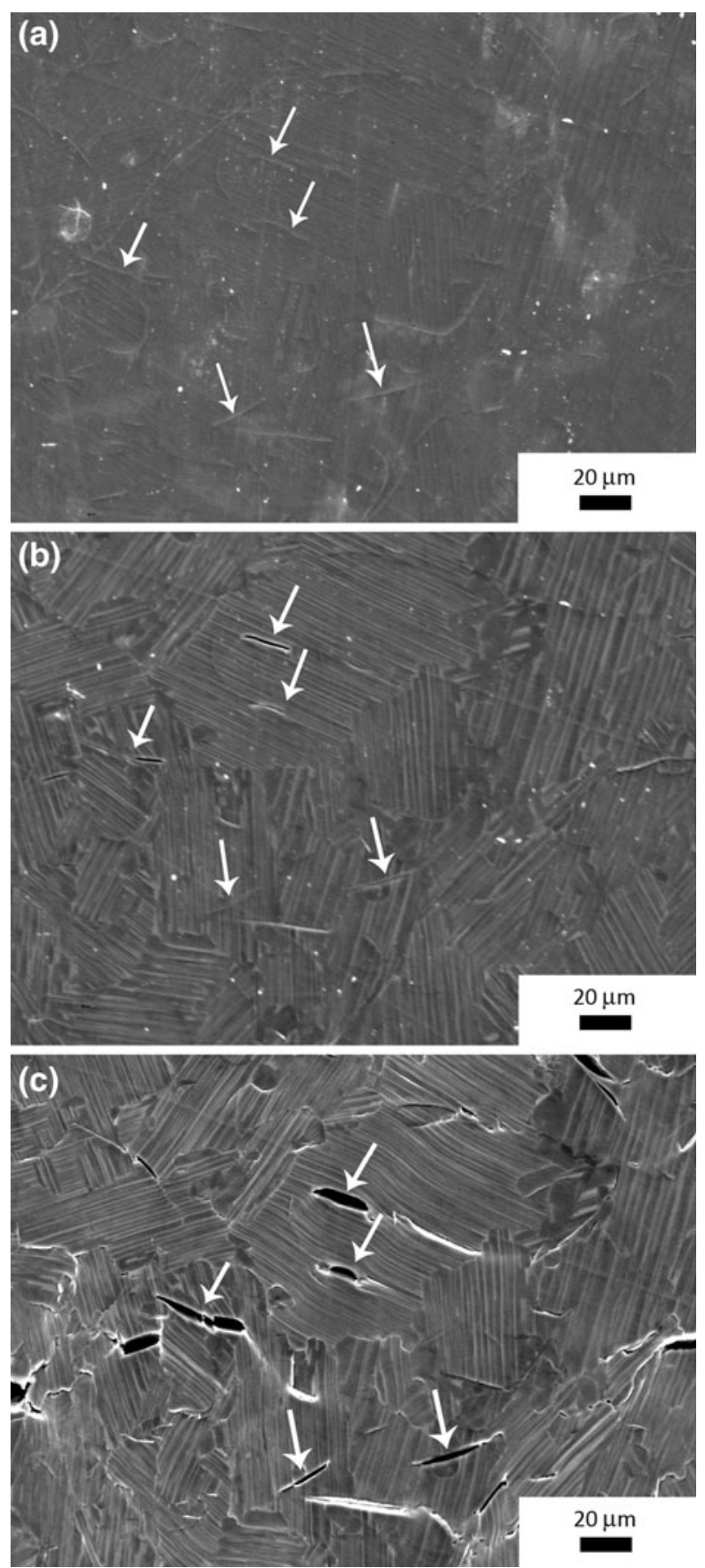

Fig. 7-SE SEM photomicrographs showing the evolution of B-rich phase cracks with increasing time for a tensile-creep test performed at $400 \mathrm{MPa}:(a)$ initial microstructure; $(b)$ secondary stage, $1 \mathrm{~h}$ and $\varepsilon \sim 0.2$ pct, $(c)$ tertiary stage, $4 \mathrm{~h}$ and $\varepsilon \sim 0.6$ pct. The loading axis is vertical.

[e.g., $>200 \mathrm{MPa}$ at $1073 \mathrm{~K}\left(800{ }^{\circ} \mathrm{C}\right)$ and $>400 \mathrm{MPa}$ at $\left.923 \mathrm{~K}\left(650^{\circ} \mathrm{C}\right)\right]$. Our in situ observations did not reveal any instabilities, even at the highest creep stresses investigated. A possible explanation for this discrepancy might be the presence of the significantly wider $\alpha_{2}$ lamellae in the Ti-45Al-2Nb-2Mn (at. pct )-0.8 vol. pct $\mathrm{TiB}_{2}$ alloy in the current study $\left(\alpha_{2}: 329 \mathrm{~nm} ; \gamma: 480 \mathrm{~nm}\right)$ compared to those investigated by Wang et al. $\left(\alpha_{2}: 20\right.$ to 

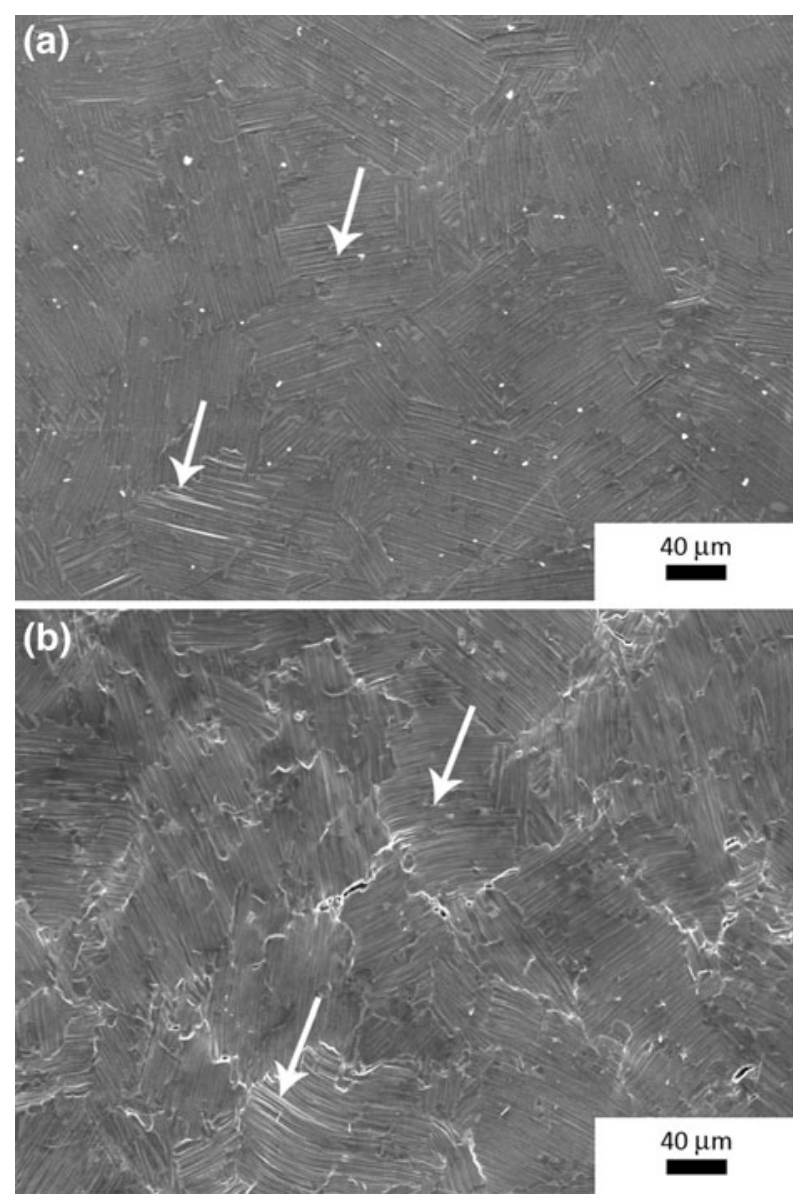

Fig. 8-SE SEM photomicrographs corresponding to a test at $425 \mathrm{MPa}$ illustrating interlamellar ledges: $(a)$ secondary-creep stage, $0.2 \mathrm{~h}, \varepsilon \sim 0.3 \mathrm{pct}$; $(b)$ tertiary-creep stage, $2 \mathrm{~h}, \varepsilon \sim 1.0$ pct. A colony boundary crack was evident near the middle of the image in (b). The loading axis is vertical.

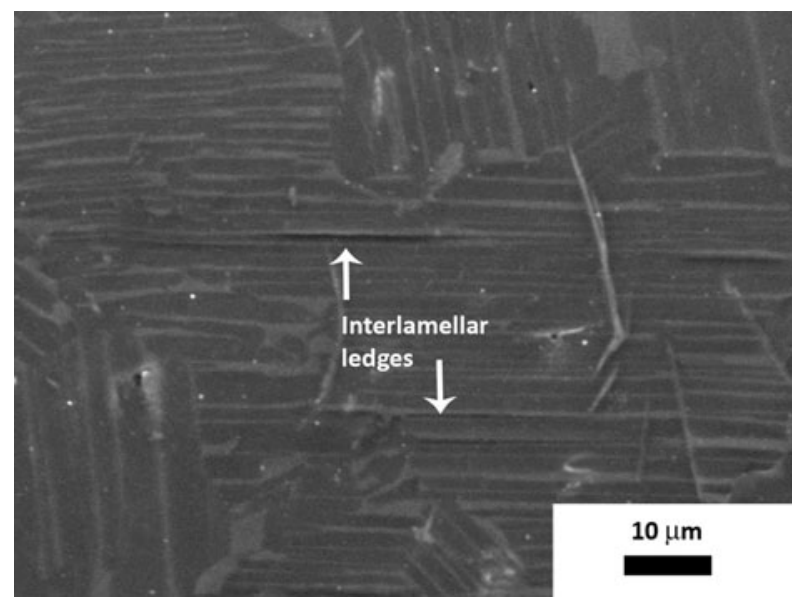

Fig. 9-SE SEM photomicrograph corresponding to a test at $450 \mathrm{MPa}$ illustrating interlamellar ledges during the secondary-creep stage $(0.33 \mathrm{~h}, \varepsilon \sim 0.1 \mathrm{pct})$.

$76 \mathrm{~nm} ; \gamma: 50$ to $500 \mathrm{~nm}$ ). In summary, the dissolution of $\alpha_{2}$ lamellae, reported previously, ${ }^{[43]}$ was not observed. This suggests there might be a critical $\alpha_{2}$ spacing above which this type of instability is prevented.

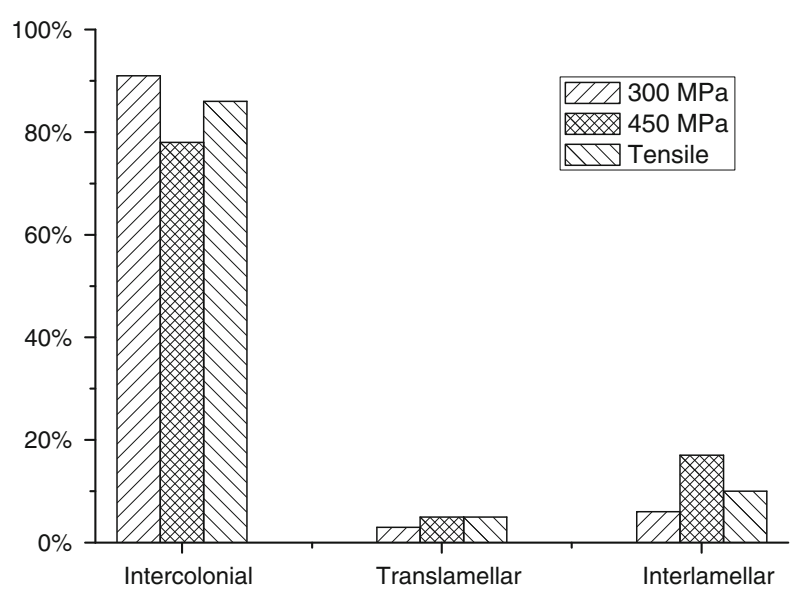

(a)

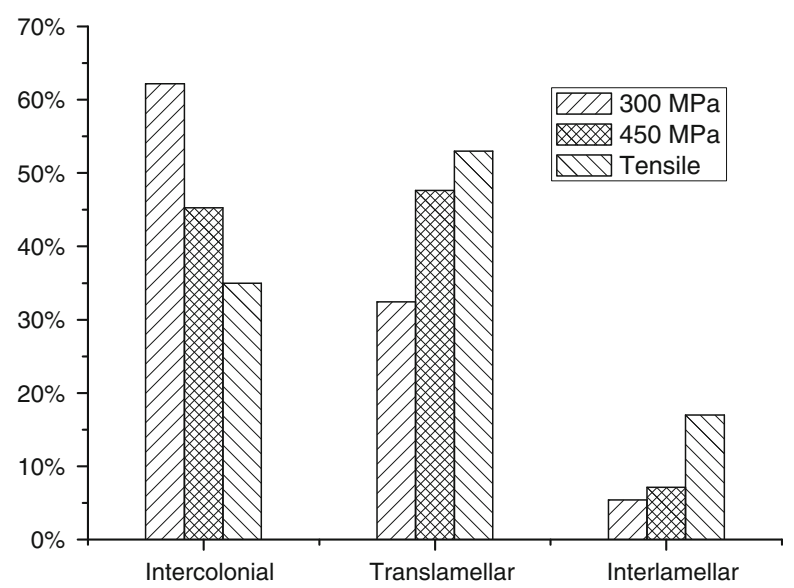

(b)

Fig. 10-Nature of the crack propagation paths in specimens deformed under tensile-creep (300 and $450 \mathrm{MPa}$ ) and tension. (a) Secondary cracks. (b) Primary crack.

Tertiary creep of $\gamma$-TiAl alloys has been attributed to the degradation of the fully lamellar structure because of phase transformations and dynamic recrystallization, to the formation of shear bands, to grain boundary sliding, and to the formation of voids. ${ }^{[15]}$ Other authors have also attributed the initiation of tertiary creep to strain incompatibilities between lamellar grains with soft and hard orientations leading to particularly elevated local stresses and, thus, to the formation of intergranular or interlamellar cracks. ${ }^{[4]}$ Our in situ observations reveal that cracks formed preferentially at colony boundaries during the early stages of deformation in low-stress tensile-creep and during the later stages of deformation in high-stress tensile-creep.

Analysis of the primary crack path further revealed that catastrophic failure was mostly due to crack propagation along grain boundaries at low stresses (up to $400 \mathrm{MPa}$ ) in tensile-creep, and across the interior of grains at higher stresses in tensile-creep and upon constant strain rate loading at the quasi-static rates investigated (see Figure 10(b)). Interlamellar crack propagation was negligible in comparison with the other two. 


\section{SUMMARY AND CONCLUSIONS}

A Ti-45Al-2Nb-2Mn-0.8 vol. pet $\mathrm{TiB}_{2}$ alloy with an average colony diameter of $126 \mu \mathrm{m}$ was tensile-creep tested at $973 \mathrm{~K}\left(700{ }^{\circ} \mathrm{C}\right)$ using stresses ranging from 300 to $450 \mathrm{MPa}$ to evaluate the influence of the stress on the occurrence of various deformation and fracture mechanisms. The in situ experiments were useful for identifying the deformation evolution. In addition, an in situ tensile experiment was performed at $973 \mathrm{~K}\left(700{ }^{\circ} \mathrm{C}\right)$. The following conclusions were reached:

1. Colony boundary sliding was observed during the secondary-creep stage. In particular, this mechanism occurred up to stresses as high as $400 \mathrm{MPa}$ and in a microstructure with a relatively large colony size $(126 \mu \mathrm{m})$. At higher stresses, colony boundary sliding was only observed during the tertiary stage.

2. Interlamellar ledges were observed during the early stages of the tensile test and the tensile-creep tests performed at the highest stresses (425 and $450 \mathrm{MPa}$ )

3 . Colony boundaries were preferential sites for crack nucleation at stresses $\leq 400 \mathrm{MPa}$. Tensile tests and tensile-creep tests at higher stresses revealed that this phenomenon was delayed but still present. In addition, cracking of B-rich phase reinforcements was observed.

4. Colony boundary cracking was the main fracture mechanism for all the tests conditions. Some interlamellar secondary cracks were also detected, but this mechanism was of less importance. Translamellar crack path segments were observed only along the primary crack. It is suggested that they connected intercolonial crack segments upon catastrophic failure.

\section{ACKNOWLEDGMENTS}

Funding from the Spanish Ministry of Science and Innovation through projects (MAT2009-14547-C02-01 and MAT2009-14547-C02-02) is acknowledged. The Madrid Regional Government partially supported this project through the ESTRUMAT grant (P2009/ MAT-1585). CJB acknowledges the support from the Spanish Ministry of Education for his sabbatical stay in Madrid (SAB2009-0045).

\section{REFERENCES}

1. D.M. Dimiduk: Mater. Sci. Eng., A, 1999, vol. 263, pp. 281-88.

2. G. Lütjering and J.C. Williams: Titanium. Enigineering Materials and Processes, Chapter 8, 2nd ed., Springer, Berlin, 2007, pp. 337-66.

3. F. Appel and M. Oehring: Titanium and Titanium Alloys. Fundamentals and Applications, Wiley, Weinheim, 2003. Chap. 4, pp. 89-152.

4. J. Beddoes, L. Zhao, P. Au, D. Dudzinski, and J. Triantafillou: Structural Intermetallics, The Minerals Metals and Materials Society, Warrendale, PA, 1997, pp. 109-18.

5. T.A. Parthasarathy, M. Keller, and M.G. Mendiratta: Scripta Metall., 1998, vol. 38 (7), pp. 1025-31.
6. T.A. Parthasarathy, M.G. Mendiratta, and D.M. Dimiduk: Scripta Metall., 1997, vol. 37 (3), pp. 315-21.

7. C.J. Boehlert, D.M. Dimiduk, and K.J. Hemker: Scripta Mater., 2002, vol. 46 (4), pp. 259-67.

8. H. Zhu, D.Y. Seo, K. Mayurama, and P. Au: Scripta Mater., 2006, vol. 54, pp. 1979-84.

9. H. Zhu, D.Y. Seo, K. Mayurama, and P. Au: Mater. Sci. Eng., A, 2008, vols. 483-484, pp. 533-36.

10. R. Muñoz-Moreno, C.J. Boehlert, E.M. Ruiz Navas, M.T. Pérez Prado, and J. Llorca: Metall. Mater. Trans. A, 2012, vol. 43A, pp. 1198-1208.

11. F. Appel, U. Brossmann, U. Christoph, S. Eggert, P. Janschek, U. Lorenz, J. Müllauer, M. Oehring, and J.D.H. Paul: Adv. Eng. Mater. Rev., 2000, vol. 2 (11), pp. 699-720.

12. M.J. Blackburn: in Technology and Application of Titanium, R.I. Jaffee and N.E. Promisel, eds., Pergamon Press, Oxford, 1970.

13. C.T. Liu and P.J. Maziasz: Intermetallics, 1997, vol. 6, pp. 653-61.

14. M.A. Morris and T. Lipe: Intermetallics, 1997, vol. 5, pp. 329-37.

15. F. Appel, J.D. Paul, and M. Oehring: $\gamma$-Titanium Aluminides, Wiley, New York, 2011.

16. J.B. Singh, G. Molénat, M. Sundararaman, S. Banerjee, G. Saada, P. Veyssière, and A. Couret: Phil. Mag., 2006, vol. 86, pp. 47-60.

17. F. Appel, U. Christoph, and M. Oehring: Mater Sc. Eng. A, 2002, vols. 329-331, pp. 780-87.

18. S. Liwen, L. Ying, M. Yue, and G. Shengkai: Rare Met., 2011, vol. 30 , p. 323.

19. F. Appel and R. Wagner: Mater. Sci. Eng. R, 1998, vol. 22, pp. $187-268$.

20. M. Hazzledine and B.K. Kad: Mater. Sci. Eng., A, 1995, vol. 192 (193), pp. 340-46.

21. T.A. Parthasarathy, P.R. Subramanian, M.G. Mendiratta, and D.M. Dimiduk: Acta Mater., 2000, vol. 48, pp. 541-51.

22. M.E. Kassner and M.T. Pérez-Prado: Fundamentals of Creep in Metals and Alloys, Elsevier, Oxford, U.K., 2004.

23. A. Gorzel and G. Sauthoff: Intermetallics, 1999, vol. 7, pp. 371-80.

24. W.J. Zhang and S.C. Deevi: Intermetallics, 2002, vol. 10, pp. $603-11$.

25. H. Zhu, D.Y. Seo, K. Maruyama, and P. Au: Scripta Mater., 2005, vol. 52, pp. 45-50.

26. Y.H. Lu, Y.G. Zhang, L.J. Qiao, Y.B. Wang, C.Q. Chen, and W.Y. Chu: Intermetallics, 2000, vol. 8, pp. 1443-45.

27. C.J. Boehlert, S.C. Longanbach, and T.R. Bieler: Phil. Mag., 2008, vol. 88 (5), pp. 641-64.

28. C.J. Boehlert, C.J. Cowen, S. Tamirisakandala, D.J. McEldowney, and D.B. Miracle: Scripta Mater., 2006, vol. 55, pp. 465-68.

29. C.J. Cowen and C.J. Boehlert: Metall. Mater. Trans. A, 2007, vol. 38A, pp. 26-34.

30. W. Chen and C.J. Boehlert: Int. J. Fatigue, 2010, vol. 32 (5), pp. 799-807.

31. "Standard Test Methods for Determining Average Grain Size", ASTM Designation E112-96e3, ASTM, West Conshohocken, PA, 1996.

32. D.E. Larsen, S. Kampe, and L. Christodoulou: Mater. Res. Soc. Symp. Proc., 1990, vol. 194, p. 285.

33. W.J. Zhang and S.C. Deevi: Intermetallics, 2002, vol. 10, pp. $603-11$.

34. W.J. Zhang and S.C. Deevi: Intermetallics, 2003, vol. 11, pp. $177-85$.

35. D.Y. Seo, H. Saari, J. Beddoes, and L. Zhao: in International Conference on Structural Intermetallics, K.J. Hemker, D.M. Dimiduk, H. Clemens, R. Darolia, H. Inui, J.M. Larsen, V.K. Sikka, M. Thomas, and J.D. Whittenberger, eds., The Minerals, Metals and Materials Society, PA, Warrendale, 2001, pp. 653-62.

36. J. Beddoes, W. Wallace, and L. Zhao: Int. Mater. Rev., 1995, vol. 40 (5), pp. 197-217.

37. M. Es-Souni, A. Bartels, and R. Wagner: Mater. Sci. Eng., A, 1995, vols. 192-193, pp. 698-706.

38. W.J. Zhang and S.C. Deevi: in International Conference on Structural Intermetallics, K.J. Hemker, D.M. Dimiduk, H. Clemens, R. Darolia, H. Inui, J.M. Larsen, V.K. Sikka, M. Thomas, and J.D. Whittenberger, eds., The Minerals, Metals and Materials Society, PA, Warrendale, 2001, pp. 699-708.

39. J. Beddoes, L. Zhao, P. Au, D. Dudzinsky, and J. Triantafillou: in International Conference on Structural Intermetallics, M.V. Nathal R. Darolia, C.T. Liu, P.L. Martin, D.B. Miracle, R. Wagner, and 
M. Yamaguchi, eds., The Minerals, Metals and Materials Society, Warrendale, PA, 1997, pp. 109-18.

40. D.B. Worth, J.W. Jones, and J.E. Allison: Metall. Mater. Trans. A, 1995, vol. 26A, pp. 2947-59.

41. L.M. Hsiung and T.G. Nieh: Intermetallics, 1999, vol. 7, pp. 821-27.

42. K. Maruyama, R. Yamamoto, H. Nakakuki, and N. Fujitsuna: Mater. Sci. Eng., A, 1997, vols. 239-240, pp. 419-28.
43. J.N. Wang and T.G. Nieh: Acta Mater., 1998, vol. 46, pp. 18871901.

44. J. Beddoes, L. Zhao, P. Au, D. Dudzinsky, and J. Triantafillou: in International Conference on Structural Intermetallics, M.V. Nathal, R. Darolia, C.T. Liu, P.L. Martin, D.B. Miracle, R. Wagner, and M. Yamaguchi, eds., The Minerals, Metals and Materials Society, Warrendale, PA, 1997, pp. 109-18. 